NASA Technical Memorandum 107506

IECEC-97053

\title{
Parametric Analysis of Cyclic Phase Change and Energy Storage in Solar Heat Receivers
}

Carsie A. Hall, III, Emmanuel K. Glakpe, and Joseph N. Cannon Howard University

Washington, $D C$

Thomas W. Kerslake

Lewis Research Center

Cleveland, Ohio

Prepared for the

32nd Intersociety Energy Conversion Engineering Conference cosponsored by AIChE, ANS, SAE, AIAA, ASME, and IEEE Honolulu, Hawaii, July 27-August 1, 1997

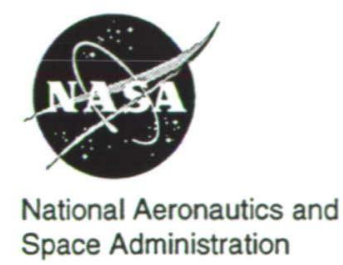




\title{
PARAMETRIC ANALYSIS OF CYCLIC PHASE CHANGE AND ENERGY STORAGE IN SOLAR HEAT RECEIVERS
}

\author{
Carsie A. Hall, III, Emmanuel K. Glakpe*, and Joseph N. Cannon \\ School of Engineering, Howard University, Washington, D.C. 20059 \\ * (202) 806-7741 (Phone) • (202) 806-5258 (Fax) \\ * glakpe@cldc.howard.edu \\ Thomas W. Kerslake \\ NASA Lewis Research Center, Cleveland, Ohio 44135 \\ (216) 433-5373 (Phone) • (216) 433-2995 (Fax) \\ Thomas.W.Kerslake@lerc.nasa.gov
}

\begin{abstract}
A parametric study on cyclic melting and freezing of an encapsulated phase change material (PCM), integrated into a solar heat receiver, has been performed. The cyclic nature of the present melt/freeze problem is relevant to latent heat thermal energy storage (LHTES) systems used to power solar Brayton engines in microgravity environments. Specifically, a physical and numerical model of the solar heat receiver component of NASA Lewis Research Center's Ground Test Demonstration (GTD) project was developed. Multi-conjugate effects such as the convective fluid flow of a low-Prandtl-number fluid, coupled with thermal conduction in the phase change material, containment tube and working fluid conduit were accounted for in the model. A single-band thermal radiation model was also included to quantify reradiative energy exchange inside the receiver and losses through the aperture. The eutectic $\mathrm{LiF}_{-} \mathrm{CaF}_{2}$ was used as the phase change material (PCM) and a mixture of $\mathrm{He} / \mathrm{Xe}$ was used as the working fluid coolant. A modified version of the computer code HOTTube was used to generate results in the two-phase regime. Results indicate that parametric changes in receiver gas inlet temperature and receiver heat input effects higher sensitivity to changes in receiver gas exit temperatures.
\end{abstract}

\section{NOMENCLATURE}

A solid cross-sectional area

C specific heat of solid regions

$c_{p} \quad$ specific heat of working fluid

f geometric view factor

$h, h * \quad$ specific enthalpy, heat transfer coefficient

$h_{s f} \quad$ PCM latent heat of fusion

L active tube or cavity length

$\dot{m}$ mass flow rate

M total number of axial nodes along tube

$\bar{n} \quad$ outer unit normal

$\begin{array}{ll}\mathbf{N} & \text { total number of tubes in receiver } \\ \mathbf{P} & \text { wetted perimeter } \\ q^{\prime \prime} & \text { heat flux } \\ \dot{Q} & \text { heat transfer rate } \\ \mathbf{r} & \text { radial location } \\ \mathbf{R} & \text { thermal resistance } \\ \mathrm{S}^{*} & \text { geometric shape factor } \\ \mathbf{t} & \text { time } \\ \mathbf{T} & \text { temperature } \\ \vec{U} & \text { velocity vector } \\ \mathbf{W} & \text { width of PCM region } \\ \mathrm{X} & \text { PCM liquid fraction } \\ \mathbf{Z} & \text { axial location } \\ \mathbf{K} & \text { shell loss function } \\ \boldsymbol{\theta} & \text { dimensionless working fluid temperature } \\ \rho & \text { density } \\ \sigma & \text { Stefan-Boltzmann constant } \\ \omega & \text { turboalternator TAC speed } \\ \text { Subscripts } \\ \text { abs } & \text { absorbed } \\ \text { ap } & \text { aperture } \\ \text { avg,max } & \text { average,maximum } \\ \text { cav } & \text { receiver cavity } \\ \text { ch } & \text { finned-tube fluid channel } \\ \mathbf{f} & \text { working fluid } \\ \text { in, out } & \text { working fluid inlet, working fluid outlet } \\ \text { ref } & \text { reference value } \\ \text { Superscripts } \\ \mathbf{n} & \text { previous time level } \\ \mathbf{n}+1 & \text { current time level } \\ & \end{array}$




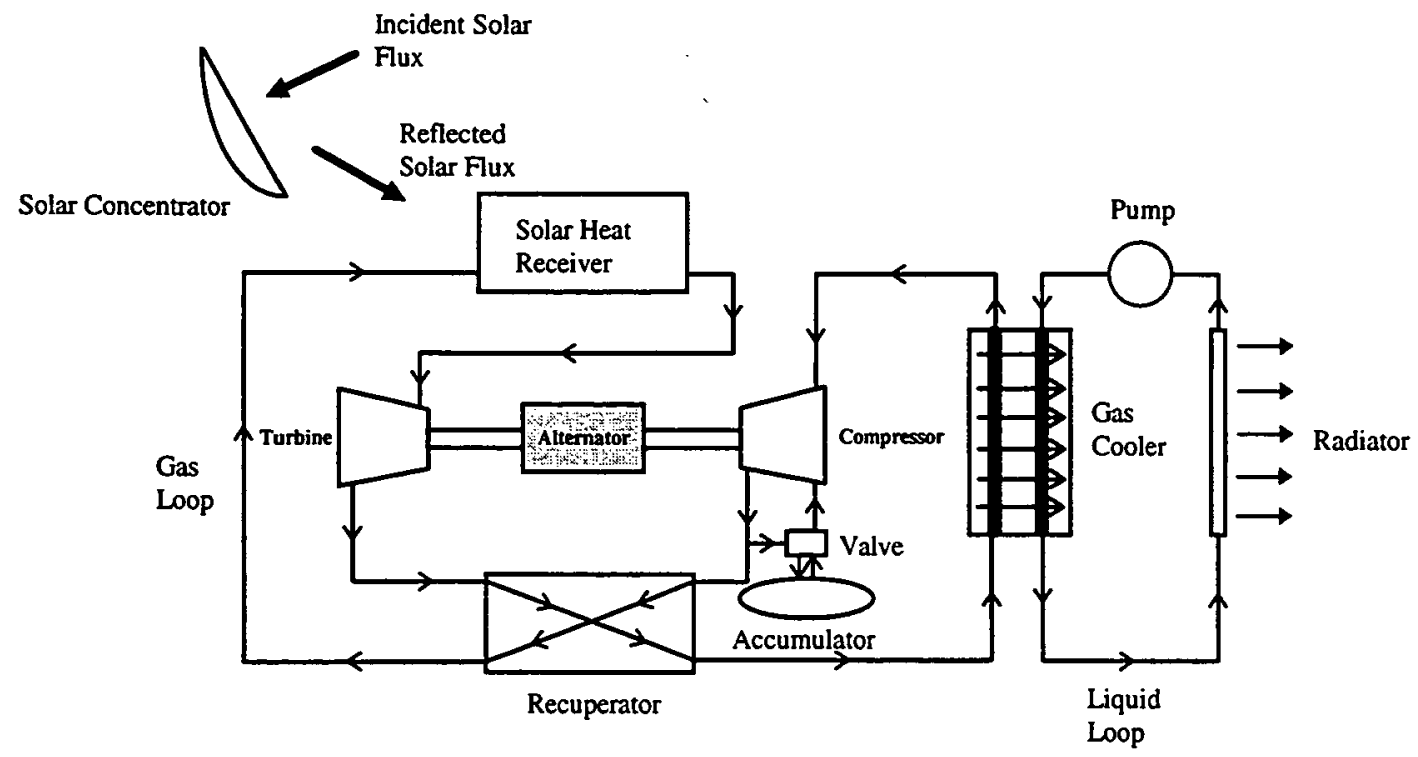

Fig. 1 Thermodynamic cycle for closed Brayton engine integrated with solar heat receiver.

\section{INTRODUCTION}

The present paper is an extension of a previous paper (Hall, III et al., 1997) by the present authors, in which a code validation exercise was undertaken. Numerical results generated by the computer code HOTTube, which modeled the thermal performance of the solar heat receiver component of the Ground Test Demonstration (GTD) project at the NASA Lewis Research Center, were compared with available experimental results.

The intermittent nature of solar energy availability for Earthorbit applications presents a particular challenge for space power management schemes during traversal into Earth's shadow (eclipse phase). One alternative to photovoltaics with battery storage is solar dynamics with latent heat thermal energy storage (LHTES) via solar heat receivers. Solar heat receivers are very instrumental components in the production of electric power via solar dynamic power systems (SDPSs). In a typical operation, the SDPS uses: 1) a concentrator to collect and focus the incident energy onto the aperture plane of a central receiver, 2) a central receiver to collect and distribute, with minimal losses, the reflected energy from the concentrator, 3) working fluid tubes aligned along the periphery of the receiver to absorb the distributed energy as heat, thus, raising the temperature of the working fluid (typically a low-Prandtl-number fluid) flowing through the tubes, 4) a turbine to expand the high temperature working fluid to produce mechanical work via a rotating shaft, 5) a compressor to circulate the working fluid through the working fluid tubes, and 6) an alternator to convert mechanical shaft motion into electric power. A recuperator is added to increase the thermal efficiency of the thermodynamic cycle (typically a closed Brayton cycle as depicted in Fig. 1).

Solar heat receivers employing encapsulated phase change materials (PCMs) have the advantage over sensible heat receivers of requiring less mass while producing higher energy storage densities. This, in turn, makes them ideal candidates for energy storage in the space environment where temperatures are sufficiently high and PCMs with high latent heats of fusion become indispensable.

Investigations on modeling and testing of solar heat receivers and/or their subcomponents employing phase change storage have appeared in the literature. Some related papers were reported by Strumpf and Coombs (1988), Sedgwick (1988, 1991), Wichner et al. (1988), Wilson and Flanery (1988), Kerslake and Ibrahim (1990), Drake (1990), Kerslake (1991), Strumpf et al. (1991, 1994), Scarda (1991), and Namkoong et al. (1995). Recently, Shaltens and Mason (1996) reported experimental results on the operational and thermal performance of the NASA Lewis Research Center's Solar Dynamic Ground Test Demonstration (GTD) project.

In the present paper, a physical and numerical model is developed to study the cyclic behavior of the solar heat receiver component of the aforementioned GTD system. A parametric analysis is undertaken to delineate sensitivities to controllable and measurable parameters such as receiver gas inlet temperature, receiver heat input, and TAC speed (via an equivalent working fluid mass flow rate). Predicting the changes in thermal performance as a result of changes in parameters is critical in - determining changes in the so-called thermal state-of-charge (SOC) of solar heat receivers. Knowledge of the SOC allows for better control strategies relating to power management schemes during such operations as peak power demand and emergency shutdowns with subsequent restarts.

\section{DESCRIPTION OF THE GTD SYSTEM}

The Ground Test Demonstration (GTD) project is the world's first full scale demonstration of reliable production of electric power via solar dynamics (SD) technology. This government/industry collaboration is carried out in the NASA Lewis Research Center's large thermal/vacuum facility (tank 6). This facility is equipped to provide simulated solar flux in high vacuum, similar to that which is encountered in Low-earth orbit 
(LEO). The primary objectives of this project are to demonstrate, using flight prototypical components, that system power delivered and system efficiency both fall within design target. Moreover, most of the hardware used in the GTD system are derived from the SD system designed for the Space Station Freedom program.

The $2 \mathrm{~kW}_{\mathrm{c}}$ (nominal) GTD system consists of an off-axis solar concentrator and solar heat receiver with latent heat thermal energy storage (LHTES), both of which are integrated with a closed Brayton engine (power conversion unit or PCU). A more complete description of the GTD system can be found in the paper by Shaltens and Mason (1996).

\section{GTD SOLAR HEAT RECEIVER MODELING}

\section{Problem Description}

The physical geometry for the present study is depicted in Fig. 2 and the more detailed single-tube model is shown in Fig. 3. It is assumed that each tube in the solar receiver is imparted with the same incident solar flux; therefore, only a single tube needs to be analyzed, with a subsequent summation over all tubes to quantify the total receiver thermal performance.

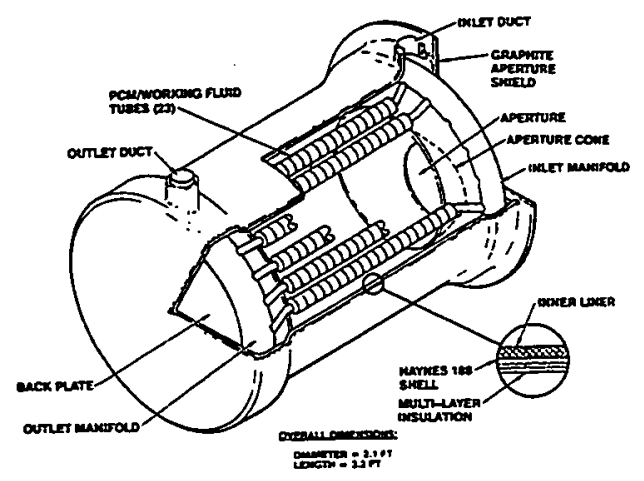

Fig. 2 GTD solar heat receiver design (provided by AlliedSignal Aerospace).

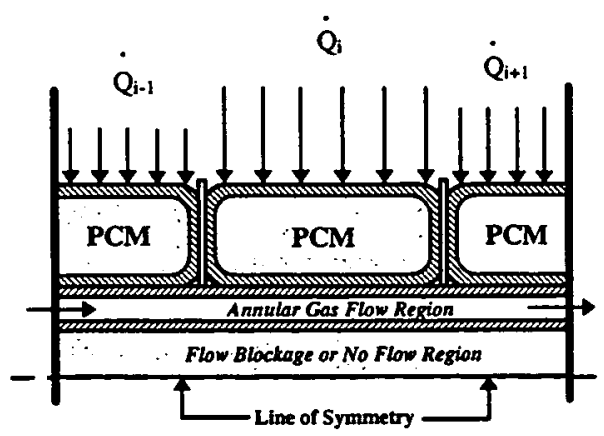

Fig. 3 Schematic of encapsulated PCM tube configuration with annular gas flow.

\section{GTD Specifications}

The specifications for the solar heat receiver of the GTD system used for modeling, in which the present numerical results reflect, are as follows:

- $\quad$ effective cavity diameter $=1.56 \mathrm{ft}(47.55 \mathrm{~cm})$

- aperture diameter $=7$ in $(17.78 \mathrm{~cm})$

- active tube length $=2 \mathrm{ft}(60.96 \mathrm{~cm})$

- canister outer diameter $=1.78$ in $(4.52 \mathrm{~cm})$

- hydraulic diameter $=0.045$ in $(0.1143 \mathrm{~cm})$

- number of tubes in the receiver $=23$

- number of canisters per tube $=24$

- $\quad$ canister material = superalloy Haynes 188

- $\quad \mathrm{PCM}=\mathrm{LiF}-\mathrm{CaF}_{2}$

- $\quad$ working fluid = helium/xenon $(\mathrm{He} / \mathrm{Xe})$

The GTD design is essentially a scale-down version of the Space Station Freedom SDPS, which was designed to yield a nominal altemator power output of $35 \mathrm{~kW}_{\mathrm{c}}$.

\section{Governing Equations}

The generalized integral equation governing the evolution of the enthalpy per unit mass for a region (denoted as $k$ ) is given by

$$
\frac{\partial}{\partial t} \int_{V_{k}} \rho_{k} h_{k} d V_{k}=-\int_{S_{k}} \rho_{k} h_{k} \vec{U}_{k} \cdot \vec{n}_{k} d S_{k}-\int_{S_{k}} \vec{q}^{\prime \prime} \cdot \vec{n}_{k} d S_{k}
$$

which is coupled to the temperature of the $\mathrm{kth}$ region by the general equation of state

$$
h_{k}-h_{\text {ref }}=\int_{T_{\text {ref }}}^{T_{k}} c_{k}\left(T_{k}{ }^{\prime}\right) d T_{k}{ }^{\prime} \cong c_{k}\left(T_{k}-T_{\text {ref }}\right)
$$

for constant $c_{k}$ where each of the $k$ regions is identified as follows: $k=1$ (outer canister region); $k=2$ (PCM region); $k=3$ (inner canister region); $k=4$ (working fluid tube region); $k=5$ (working fluid region). In the solid regions and liquid PCM region (due to the assumption of no convective motion), $\vec{U}_{k}=\overrightarrow{0}$.

\section{Discrete Representations}

It should be stated at the outset that the containment canister outer and inner regions, along with the working fluid tube region, are all considered radially lumped. As a result, the radial index $\mathrm{j}$ corresponding to the representative temperatures of those regions are $j=1, j=j \max -1$, and $j=j \max$ for the outer canister, inner canister, and working fluid tube regions, respectively. The remaining PCM region is divided into jmax-3 nodes, for each ith axial location along the tube.

Applying Eq. 1 to a control volume at the ith outer canister location $(k=1)$ along the tube results in 


$$
(\rho A)_{1} \Delta z\left(\frac{h_{i_{i, j}}^{n+1}-h_{1_{i, j}}^{n}}{\Delta t}\right)=\dot{Q}_{a b s_{i}}^{n}-\left(\frac{T_{2_{i, j+1}}^{n}-T_{1_{i, j}}^{n}}{R_{1_{i, j+1}}}\right)
$$

where $i$ is the discrete index corresponding to the axial direction $(i=1,2, \ldots \ldots, M) ; j$ is the discrete index corresponding to the radial direction $(j=1,2, \ldots \ldots, j \max ) ; n$ is the discrete index for the previous time level and $n+1$ is the discrete index for the current time level. For the PCM region $(k=2)$, the discrete equation is expressed as

$$
(\rho A)_{2}\left(\frac{h_{i_{i, j}}^{n+1}-h_{2_{i, j}}^{n}}{\Delta t}\right)=\left(\frac{T_{2_{i, j+1}}^{n}-T_{2_{i, j}}^{n}}{R_{2_{i, j+1}}}\right)-\left(\frac{T_{2_{i, j-1}}^{n}-T_{2_{i, j}}^{n}}{R_{2_{i, j-1}}}\right)
$$

which is valid in the region $2 \leq \mathrm{j} \leq \mathrm{jmax}-2$. Another important consideration is that since the zero reference level for the PCM enthalpy per unit mass is in the subcooled regime, and is somewhat arbitrary, a "flag" based on temperature is used to indicate proximity to the melting point. As a result, an additional equation governing the fraction of PCM mass in the liquid phase is given by

$$
\frac{m_{i, j} h_{s f}}{W}\left(\frac{X_{i, j}^{n+1}-X_{i, j}^{n}}{\Delta t}\right)=\left(\frac{T_{2_{i, j+1}}^{n}-T_{i_{i, j}}^{n}}{R_{2_{i, j+1}}}\right)-\left(\frac{T_{2_{i, j-1}}^{n}-T_{2_{i, j}}^{n}}{R_{2_{i, j-1}}}\right)
$$

where the liquid fraction for the ith axial canister location and jth node is in the range $0 \leq X_{i, j} \leq 1$. This scheme can be considered a hybrid between the enthalpy method and the front tracking method, since the interface is not tracked explicitly but an additional equation is used. Furthermore, the discrete equations governing the evolution of enthalpy per unit mass for the canister inner region $(k=3)$ and working fluid tube region $(k=4)$ are derived as

$$
\begin{array}{r}
(\rho A)_{3}\left(\frac{h_{3_{i, j}}^{n+1}-h_{3_{i, j}}^{n}}{\Delta t}\right)=\left(\frac{T_{4_{i, j+1}}^{n}-T_{3_{i, j}}^{n}}{R_{3_{i, j+1}}}\right)-\left(\frac{T_{2_{i, j-1}}^{n}-T_{i_{i, j}}^{n}}{R_{3_{i, j-1}}}\right) \\
(\rho A)_{4} \Delta z\left(\frac{h_{4_{i, j}}^{n+1}-h_{4_{i, j}}^{n}}{\Delta t}\right)=\dot{Q}_{f_{i}}^{n}-\left(\frac{T_{3_{i, j-1}}^{n}-T_{4_{i, j}}^{n}}{R_{4_{i, j-1}}}\right) \\
+\left(\frac{T_{4_{i+1, j}}^{n}-T_{4_{i, j}}^{n}}{R_{4_{i+1, j}}}\right)+\left(\frac{T_{4_{i-1, j}}^{n}-T_{4_{i, j}}^{n}}{R_{4_{i-1, j}}}\right) \\
\hline
\end{array}
$$

For the working fluid region $(k=5)$, a 1-D, quasi-steady model for the axial transport of enthalpy per unit mass is used. A modified version of the closed-form solution given by (for an isothermal wall condition)

$$
\theta(z)=\frac{T_{s}-T_{f}}{T_{s}-T_{i n}}=e^{-\left(\frac{P n_{z} z}{\dot{m} c_{p}}\right)}
$$

is written for the present configuration as

$$
\theta_{i}^{n+1}=\frac{T_{s_{i}}^{n+1}-T_{f_{i}}^{n+1}}{T_{s_{i}}^{n+1}-T_{i n_{i}}^{n+1}}=e^{-\left(\frac{P_{c h} S^{*} h^{*} \Delta z}{\dot{m}_{c h} c_{p}}\right)}
$$

where $P_{c h}$ is the channel wetted perimeter, $\dot{m}_{c h}$ is the channel mass flow rate, and $S^{*}$ is a geometric shape factor (estimated to be in the range $1 \leq S^{*} \leq 1.2$ ), used to account for the degree of departure from triangularity of the finned-tube cross-section. Finally, the net rate of axially convected enthalpy, used in Eq. 7, is expressed as

$$
\underline{\dot{Q}_{f_{i}}^{n}=\dot{m} c_{p}\left(T_{f_{i-1}}^{n}-T_{f_{i}}^{n}\right)}
$$

\section{Thermal Radiation Model}

An energy balance on the ith node results in the following equation goveming the net rate of energy absorbed at the ith node:

$$
\dot{Q}_{a b s_{i}}=\dot{Q}_{i}+\dot{Q}_{R_{i}}-\dot{Q}_{a p_{i}}-\dot{Q}_{\text {shelli }}
$$

where for $i=1,2, \ldots \ldots . . M$

$$
\begin{gathered}
\dot{Q}_{R_{i}}=\frac{A_{i}}{N} \sigma \sum_{j=1}^{M+2} f_{i-j}\left(T_{j}^{4}-T_{i}^{4}\right) \\
\dot{Q}_{a p_{i}}=\frac{A_{i}}{N} \sigma \dot{f}_{i-a p}\left(T_{i}^{4}-T_{a p}^{4}\right)
\end{gathered}
$$

and the receiver shell loss per node is given by

$$
\dot{Q}_{\text {shell }_{i}}=\frac{\kappa\left(T_{\text {avg }}\right)}{N M}
$$

In this equation, the function $\kappa\left(T_{\text {avg }}\right)$ is recommended by Ensworth et al. (1996) to be

$$
\kappa\left(T_{\text {avg }}\right)=b\left(\frac{T_{\text {avg }}}{T_{\text {ref }}}\right)^{4}
$$

where $b=0.82, T_{\text {ref }}=1860 R(1033 \mathrm{~K})$, and $T_{\text {avg }}$ is the instantaneous, spatially-averaged canister outer surface temperature, given by

$$
T_{\text {avg }}(t)=\frac{1}{L_{c a v}} \int_{0}^{L_{c a v}} T_{1}(z, t) d z
$$




\section{Modified HOTTube Code}

The numerical results presented in this present paper were generated using a modified version of the computer code HOTTube, which is a transient, time-explicit, axisymmetric total receiver thermal analysis code. HOTTube was initially developed by AlliedSignal Aerospace for the Space Station Freedom solar heat receiver. For a more complete description of modified HOTTube, including grid size and time step requirements, see the paper by Hall, III et al. (1997).

\section{RESULTS AND DISCUSSION}

The results presented in this section pertain to a baseline maximum insolation orbit for the orbital altitude corresponding to 92 minutes total orbit time with 28 minutes of eclipse. This maximum insolation of approximately 1.26 suns $(1$ sun $=1.37$ $\mathrm{kW} / \mathrm{m}^{2}$ ) is incidentally, the maximum output capability of the solar simulator lamps of the GTD system. The corresponding rate of energy crossing the aperture plane of the receiver during the simulated sun period is approximately $12.6 \mathrm{~kW}$. Another point of interest is a newly determined SD-Mir design point (determined by AlliedSignal Aerospace), which corresponds to a receiver heat input of $15.1 \mathrm{~kW}$ and TAC operating speed of 53,000 RPM. It should be further pointed out that due to the maximum power output capability of the GTD solar simulator lamps, a pseudo-SDMir design point was effected (in the GTD experiment) by increasing the sun period to $77 \mathrm{~min}$ during the first two cycles to get the equivalent amount of energy into the receiver.

The nominal SD-Mir design point operating speed of the GTD engine's turboaltemator work-producing shaft is 53,000 RPM, which yields a working fluid mass flow rate of approximately $0.3385 \mathrm{lb} / \mathrm{s}(154 \mathrm{~g} / \mathrm{s})$. A map of TAC speed versus mass flow rate is provided by Shaltens and Mason (1996), from which a linear curve fit performed by the present authors is given by

$$
\dot{m}=0.0629+5.2 \times 10^{-6} \omega
$$

where $\omega$ is the TAC speed in RPM and $m$ is the working fluid mass flow rate in $1 b_{m} / s$.

\section{Solar Receiver Energy Balance}

As pointed out in Hall, III et al. (1997), an important consideration in the numerical prediction of the solar receiver's thermal performance is the instantaneous overall energy balance. This is done to account for every unit of energy crossing the aperture plane per unit time. Fig. 4 is a plot of the solar receiver's energy budget for the SD-Mir design point. The profile for the rate of energy crossing the aperture plane (labeled

“ $\dot{Q}_{\text {in }}$ ") resembles a square pulse function, which illustrates the switching nature of consecutive sun periods and eclipse periods.

If the receiver is truly balanced, then the sum (labeled " $\dot{Q}_{\text {lotal }}$ ") of the rate of energy extracted by the gas (labeled " $\dot{Q}_{\text {gas }}$ "), rate of energy lost by reradiation through the aperture and rate of energy lost through the receiver shell (labeled " $\dot{Q}_{\text {loss }}$ "), and rate of energy stored inside the receiver (labeled " $\dot{Q}_{\text {stor }}$ ") should also follow this square pulse function. This is indeed the case, as shown in Fig. 4, with a maximum error of less than 3 percent. This small error is primarily due to the receiver shell heat loss approximation.

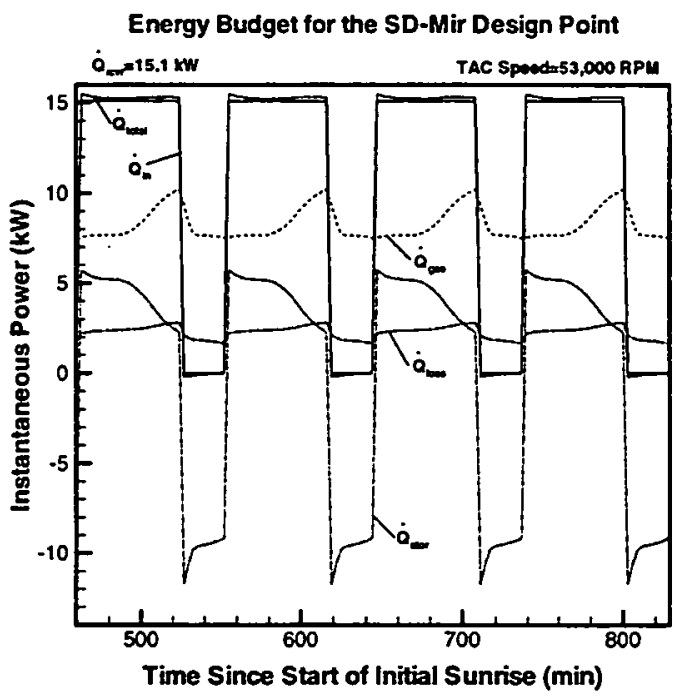

Fig. 4 Solar receiver energy balance for the SD-Mir design point operating conditions.

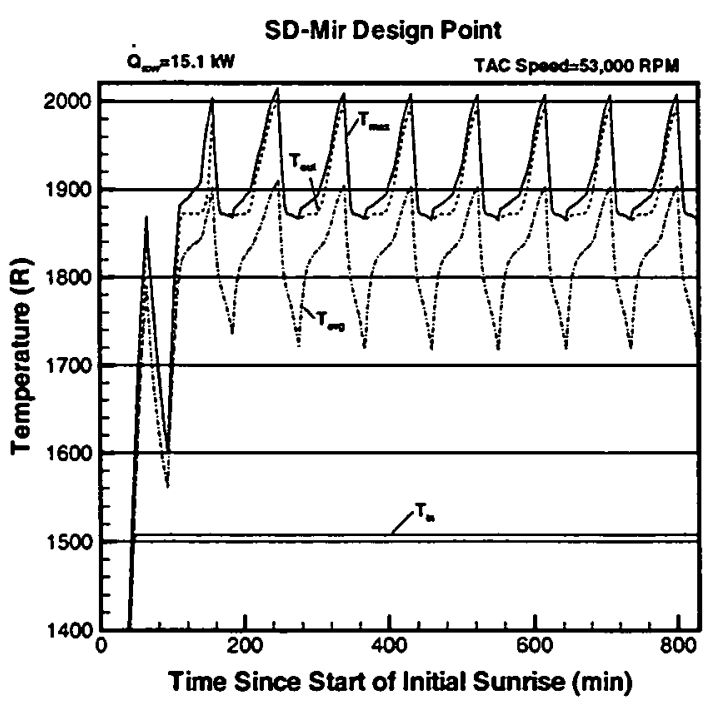

Fig. 5 Numerical prediction of maximum canister temperature, average canister temperature, and receiver gas exit temperature over 9 orbit cycles. 


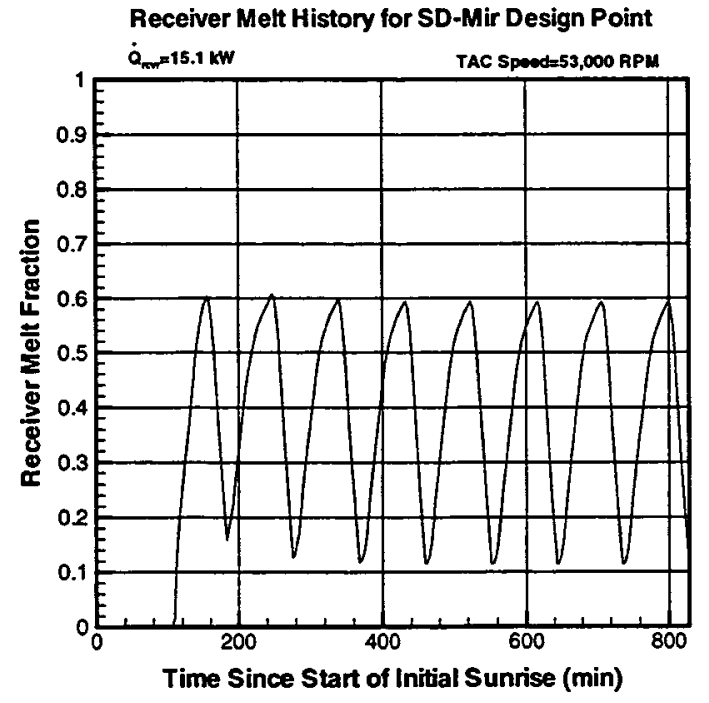

Fig. 6 Numerical prediction of the total fraction of PCM in the liquid phase over 9 orbit cycles.

\section{Temperature and Melt Fraction Predictions}

Fig. 5 shows the temporal progression of maximum canister outer surface temperature, average canister outer surface temperature, and receiver gas exit temperature from startup to 9 orbit cycles. The receiver heat input is fixed at $15.1 \mathrm{~kW}$ and the TAC speed varies from zero at startup to $53,000 \mathrm{RPM}$. The receiver gas inlet temperature is fixed at $1508 \mathrm{R}(838 \mathrm{~K})$.

The transient operation for the orbital simulations performed to reach the SD-Mir design point is detailed as follows:

1) the startup mass flow rate is fixed at $0.005 \mathrm{lb}_{\mathrm{m}} / \mathrm{s}(2.3 \mathrm{~g} / \mathrm{s})$ until the maximum canister temperature reaches $1900 \mathrm{R}$ $(1056 \mathrm{~K})$, after which it is increased to $0.3385 \mathrm{lb} / \mathrm{m}(154$ $\mathrm{g} / \mathrm{s}$ ) (this occurs during the $2^{\text {nd }}$ cycle); faster heatup of the receiver is effected as a result;

2) also during startup, the receiver gas exit temperature is fed back to the receiver inlet until the receiver inlet reaches $1508 \mathrm{R}(838 \mathrm{~K})$, which is accomplished during the $1^{\text {st }}$ cycle; this is an expedient computational scheme that advances the numerical solution to the point where higher fidelity modeling can be initiated;

3) during the first two cycles, the total orbit period is $105 \mathrm{~min}$ with a sun period of $77 \mathrm{~min}$, after which the total orbit period is changed to the baseline $92 \mathrm{~min}$ with a sun period of $64 \mathrm{~min}$;

From the figure, it is shown that balanced orbit conditions are reached on the $4^{\text {th }}$ orbit. A balanced obit is declared when the difference between all calculated temperatures is less than $2 \mathrm{R}$ $(1.1 \mathrm{~K})$ between successive sunrise and sunset conditions. It is further observed that over most of the orbit cycles

$$
\mathrm{T}_{\max }>\mathrm{T}_{\text {out }}>\mathrm{T}_{\text {avg }}
$$

which is what is typically observed during experimental test runs. In addition, perusal of the numerical data reveals that the maximum canister, average canister, and receiver gas exit temperatures at sunset are approximately $2007 \mathrm{R}(1115 \mathrm{~K}), 1904$ $\mathrm{R}(1058 \mathrm{~K})$, and $1994 \mathrm{R}(1108 \mathrm{~K})$, respectively, for the balanced orbits. These temperatures indicate that during the sun period, a local superheat event occurred that caused a sharp rise in receiver gas exit temperature significantly beyond the PCM melting point of $1873 \mathrm{R}(1040 \mathrm{~K})$. This is corroborated by the significant rise in receiver gas heat input as shown in Fig. 4, where over the sun period, the gas heat input increases from a steady value of approximately $7.7 \mathrm{~kW}$ to approximately $10.2 \mathrm{~kW}$ at sunset.

The corresponding fraction of receiver PCM in the liquid phase is illustrated in Fig. 6. Recall that the melting point of LiF$\mathrm{CaF}_{2}$ is $1873 \mathrm{R}(1040 \mathrm{~K})$ and its latent heat of fusion is 340 $\mathrm{Btu} / 1 \mathrm{~b}_{\mathrm{m}}(789 \mathrm{~kJ} / \mathrm{kg})$. For the GTD solar heat receiver, the total mass of PCM is $53 \mathrm{lb}_{\mathrm{m}}(24 \mathrm{~kg})$ which corresponds to a maximum latent storage capacity of $18,020 \mathrm{Btu}(19 \mathrm{MJ}$ or $5.3 \mathrm{~kW} \mathrm{hr})$. It is observed that the maximum liquid fraction, which occurs on sunset for all representative cycles, reaches a maximum of approximately 61 percent during the heatup phase and 59 percent during the balanced orbit phases. However, at the end of the eclipse phase (sunrise), approximately 12 percent of liquid PCM remains in the receiver for the balanced orbit cycles.

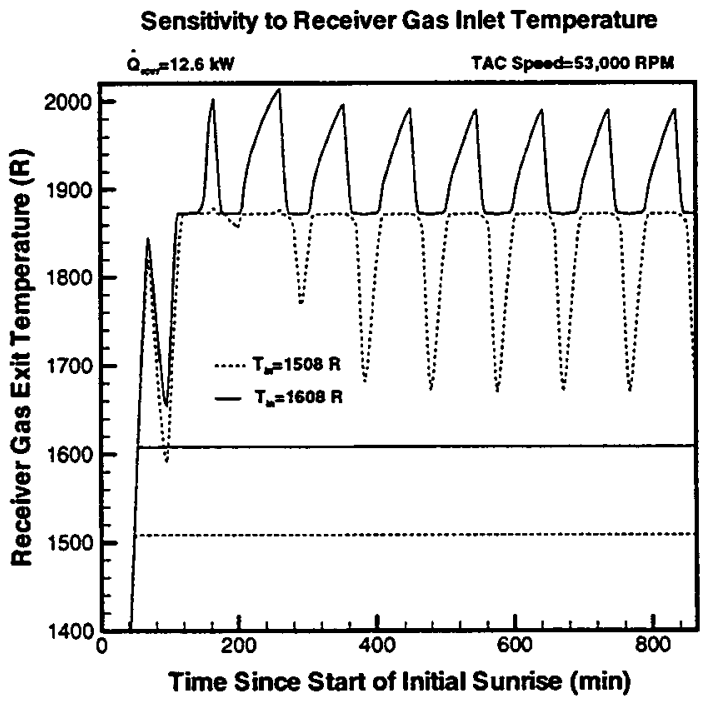

Fig. 7 Effect of receiver gas inlet temperature on receiver gas exit temperature over 9 orbit cycles for the pseudo-SD-Mir design point. 


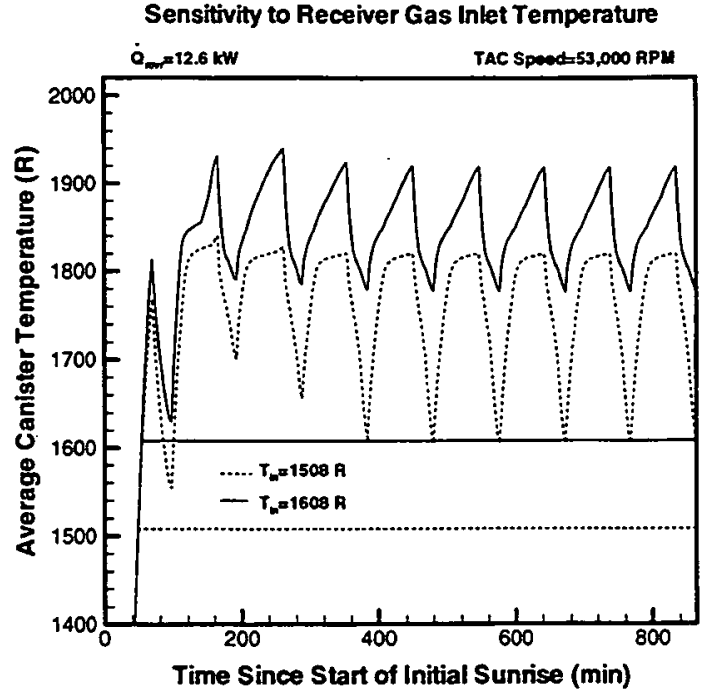

Fig. 8 Effect of receiver gas inlet temperature on average canister surface temperature over 9 orbit cycles for the pseudo-SD-Mir design point.

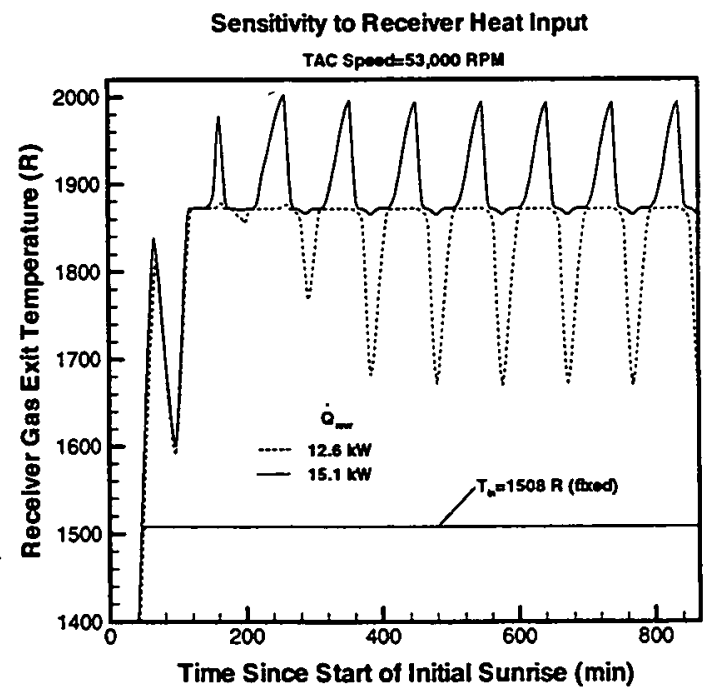

Fig. 9 Effect of receiver heat input on receiver gas exit temperature over 9 orbit cycles.

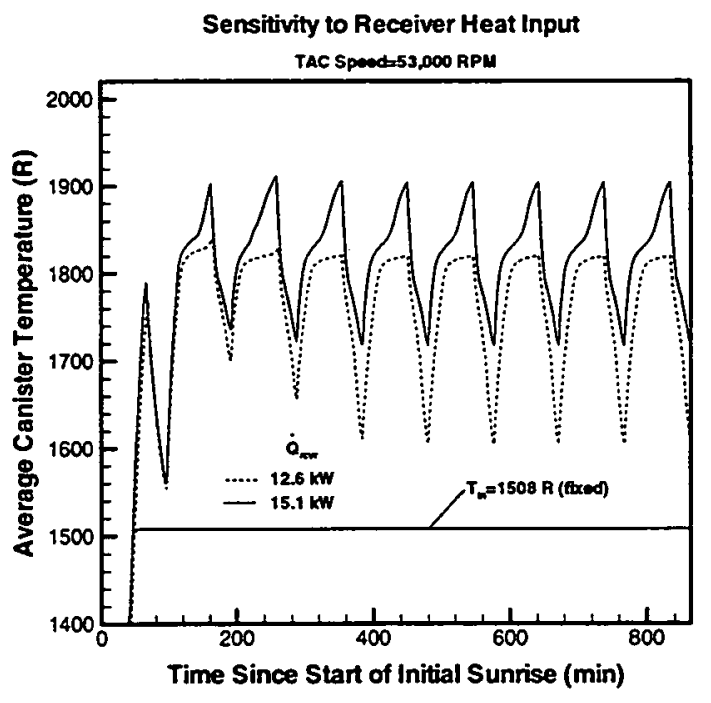

Fig. 10 Effect of receiver heat input on average canister surface temperature over 9 orbit cycles.

\section{Parametric Sensitivity}

Shown in Figs. 7 and 8 are the relative sensitivities of receiver gas exit temperature and average canister surface temperature to receiver gas inlet temperature. Sensitivities are shown for an increase in receiver gas inlet temperature from $1508 \mathrm{R}(838 \mathrm{~K})$ to $1608 \mathrm{R}(893 \mathrm{~K})$. For this case, the receiver heat input is fixed at $12.6 \mathrm{~kW}$ and the TAC speed is held at 53,000 RPM, which corresponds to a gas mass flow rate of $0.3385 \mathrm{lb}_{\mathrm{m}} / \mathrm{s}(154 \mathrm{~g} / \mathrm{s})$. It appears that the receiver gas exit temperature is more responsive to the change in receiver gas inlet temperature, as expected. This is primarily due to the smaller thermal interaction time scale for the gas than for the diffusion time scale through the solid layers of canister material and PCM. In fact, over the balanced orbit cycles, the $100 \mathrm{R}(56 \mathrm{~K})$ increment in receiver inlet temperature effects a $118 \mathrm{R}(66 \mathrm{~K})$ increase in receiver gas exit temperature at sunset and a $99 \mathrm{R}(55 \mathrm{~K})$ increase in average canister surface temperature at sunset. These are increases over that which occurs at sunset for a receiver inlet temperature of $1508 \mathrm{R}(838 \mathrm{~K})$. The corresponding changes for sunrise conditions over the balanced orbit cycles result in a $202 \mathrm{R}(112 \mathrm{~K})$ increase in receiver gas exit temperature and a $171 \mathrm{R}(95 \mathrm{~K})$ increase in average canister surface temperature. Also observed in the figures are the qualitative changes in the shapes of the temperature profiles, which for the higher gas inlet temperature, results in a $\Lambda$-shape over the entire orbit period. This is an indication that the system moves away from orbital steady-state conditions.

The sensitivities to changes in receiver heat input are illustrated in Figs. 9 and 10. For these cases, the receiver gas inlet temperature is fixed at $1508 \mathrm{R}(838 \mathrm{~K})$ and the TAC speed is held at 53,000 RPM, which corresponds to a gas mass flow rate of $0.3385 \mathrm{lb}_{\mathrm{m}} / \mathrm{s}(154 \mathrm{~g} / \mathrm{s})$. The receiver heat input is varied from the pseudo-SD-Mir design point value of $12.6 \mathrm{~kW}$ to the actual SD-Mir design point value of $15.1 \mathrm{~kW}$. In the balanced orbit regime, the additional $2.5 \mathrm{~kW}$ results in an increase in receiver gas exit temperature of $122 \mathrm{R}(68 \mathrm{~K})$ at sunset and an increase of 
$194 \mathrm{R}(108 \mathrm{~K})$ at sunrise. Similarly, the additional $2.5 \mathrm{~kW}$ causes an $84 \mathrm{R}(47 \mathrm{~K})$ increase in average canister surface temperature at sunset and a $112 \mathrm{R}(62 \mathrm{~K})$ increase at sunrise. In Fig. 9, the qualitative $\Lambda$-shape is retained for the receiver gas exit temperature whereas in Fig. 10, there is a departure from the $\Lambda$-shape trend for the average canister surface temperature. This departure is attributed to a local superheat event that occurred in one of the containment canisters.

\section{CONCLUSIONS}

A physical and numerical model of the solar heat receiver component of NASA Lewis Research Center's Solar Dynamic (SD) Ground Test Demonstration (GTD) project has been developed. A parametric study was performed to delineate changes in receiver gas exit temperature and average canister surface temperature due to changes in receiver gas inlet temperature and receiver heat input. Results showed that receiver gas exit temperatures were more sensitive to changes in receiver gas-inlet temperatures. It was also shown that changes in receiver heat input effects a higher sensitivity to changes in receiver gas exit temperatures.

\section{ACKNOWLEDGMENT}

The work reported in this paper was sponsored by a grant to Howard University from the NASA Lewis Research Center under grant number NAG3-1907.

\section{REFERENCES}

Drake, J.B., 1990, "Modeling Convective Marangoni Flows with Void Movement in the Presence of Solid-Liquid Phase Change," ORNL TM - 6516.

Ensworth, C., McKissock; D., and Mason, L., 1996, "Comparison of CCEP with GTD Test Data," Intemal Memorandum, Update \#3.

Hall, III, C.A., Glakpe, E.K., Cannon, J.N., and Kerslake, T.W., 1997, "Modeling Cyclic Phase Change and Energy Storage in Solar Heat Receivers," Proceedings of the $32^{\text {nd }}$ AIAA Thermophysics Conference, Atlanta, Georgia.

Kerslake, T.W. and Ibrahim, M.B., 1990, "Two-Dimensional Model of a Space Station Freedom Thermal Energy Storage Canister," NASA TM 103124 and Proceedings of the 25th Intersociety Energy Conversion Engineering Conference, 'Reno, NV.
Kerslake, T.W., 1991, "Experiments with Phase Change Thermal Energy Storage Canisters for Space Station Freedom," NASA TM 104427 and Proceedings of the 26th Intersociety Energy Conversion Engineering Conference, Boston, MA.

Namkoong, D., Jacqmin, D., and Szaniszlo, A., 1995, "Effect of Microgravity on Material Undergoing Melting and Freezing - The TES Experiment," Proceedings of the ALAA 33rd Aerospace Sciences Meeting and Exhibit, Reno, NV.

Sedgwick, L.M., 1988, "Solar Dynamic Heat Receiver Technology Design Analysis Report," Boeing Report D180 29711-1.

Sedgwick, L.M., 1991, "Advanced Development Receiver Thermal Vacuum Tests with Cold Wall," NASA Contractor Report 187092.

Shaltens, R.K. and Mason, L.S., 1996, "Early Results from Solar Dynamic Space Power System Testing," AIAA Journal of Propulsion and Power, Vol. 12, No. 5, pp. 852-858.

Skarda, J.R.L., 1991, "Thermal Modeling with Solid/Liquid Phase Change of the Thermal Energy Storage Experiment," NASA TM 103770.

Strumpf, H. and Coombs, M.G., 1988, "Solar Receiver Experiment for the Hybrid Space Station Brayton Engine," Proceedings of the ASME Solar Energy Division Conference, San Diego, CA.

Strumpf, H., Avanessian, V., and Ghafourian, R., 1991, "Design Analysis and Life Prediction for the Brayton Engine Solar Receiver for the Space Station Freedom Solar Dynamic Option," Proceedings of the 26th Intersociety Energy Conversion Engineering Conference, Boston, MA.

Strumpf, H., Avanessian, V., and Ghafourian, R., 1994, "Design Analysis and Containment Canister Life Prediction for a Brayton Engine Solar Receiver for Space Station," ASME Journal of Solar Energy Engineering, Vol. 116, pp. 142147.

Wichner, R.P., Solomon, A.D., Drake, J.B., and Williams, P.T., 1988, "Thermal Analysis of Heat Storage Canisters for a Solar Dynamic Space Power System," ORNL TM - 10665.

Wilson, D.G. and Flanery, R.E., 1988, "Modeling Cyclic Melting and Freezing in a Hollow Metal Canister," ORNL TM - 6497 . 
Public reporting burden for this collection of intormation is estimated to average 1 hour per response, including the time for reviewing instructions, searching existing data sources. gathering and maintaining the data needed, and completing and reviewing the collection of information. Send comments regarding this burden estimate or any other aspect of this collection of information, including suggestions for reducing this burden, to Washington Headquarters Services, Directorate for Information Operations and Reports, 1215 Jefferson Davis Highway, Suite 1204, Artington, VA 22202-4302, and to the Office of Management and Budget, Paperwork Reduction Project (0704-0188), Washington, DC 20503.

\begin{tabular}{|l|c|r|}
\hline 1. AGENCY USE ONLY (Leave blank) & $\begin{array}{c}\text { 2. REPORT DATE } \\
\text { July } 1997\end{array}$ & $\begin{array}{r}\text { 3. REPORT TYPE AND DATES COVERED } \\
\text { Technical Memorandum }\end{array}$ \\
\hline
\end{tabular}

\section{TITLE AND SUBTITLE}

5. FUNDING NUMBERS

Parametric Analysis of Cyclic Phase Change and Energy Storage in Solar Heat Receivers

6. AUTHOR(S)

WU-547-10-41

Carsie A. Hall, III, Emmanuel K. Glakpe, Joseph N. Cannon, and Thomas W. Kerslake

7. PERFORMING ORGANIZATION NAME(S) AND ADDRESS(ES)

8. PERFORMING ORGANIZATION REPORT NUMBER

National Aeronautics and Space Administration

Lewis Research Center

Cleveland, Ohio 44135-3191

E-10808

9. SPONSORINGMONITORING AGENCY NAME(S) AND ADORESS(ES)

National Aeronautics and Space Administration

Washington, DC 20546-0001

10. SPONSORING/MONITORING AGENCY REPORT NUMBER

NASA TM-107506

IECEC-97053

11. SUPPLEMENTARY NOTES

Prepared for the 32nd Intersociety Energy Conversion Engineering Conference cosponsored by AIChE, ANS, SAE, AIAA, ASME, and IEEE, Honolulu, Hawaii, July 27-August 1, 1997. Carsie A. Hall, III, Emmanuel K. Glakpe, and Joseph N. Cannon, School of Engineering, Howard University, Washington, DC 20059 (work funded by NASA Grant NAG3-1907); Thomas W. Kerslake, NASA Lewis Research Center. Responsible person, Thomas W. Kerslake, organization code 6920, (216) 433-5373.

12a. DISTRIBUTION/AVAILABILITY STATEMENT

12b. DISTRIBUTION CODE

Unclassified - Unlimited

Subject Category 20

This publication is available from the NASA Center for AeroSpace Information, (301) 621-0390.

13. ABSTRACT (Maximum 200 words)

A parametric study on cyclic melting and freezing of an encapsulated phase change material (PCM), integrated into a solar heat receiver, has been performed. The cyclic nature of the present melt/freeze problem is relevant to latent heat thermal energy storage (LHTES) systems used to power solar Brayton engines in microgravity environments. Specifically, a physical and numerical model of the solar heat receiver component of NASA Lewis Research Center's Ground Test Demonstration (GTD) project was developed. Multi-conjugate effects such as the convective fluid flow of a lowPrandtl-number fluid, coupled with thermal conduction in the phase change material, containment tube and working fluid conduit were accounted for in the model. A single-band thermal radiation model was also included to quantify reradiative energy exchange inside the receiver and losses through the aperture. The eutectic $\mathrm{LiF}-\mathrm{CaF}_{2}$ was used as the phase change material (PCM) and a mixture of He/Xe was used as the working fluid coolant. A modified version of the computer code HOTTube was used to generate results in the two-phase regime. Results indicate that parametric changes in receiver gas inlet temperature and receiver heat input effects higher sensitivity to changes in receiver gas exit temperatures.

\section{SUBJECT TERMS}

Phase change materials; Heat storage; Solar dynamic power systems; Molten salts; Solar energy; Space stations

\begin{tabular}{|c|c|}
\hline $\begin{array}{c}\text { 17. SECURITY CLASSIFICATION } \\
\text { OF REPORT } \\
\text { Unclassified }\end{array}$ & $\begin{array}{c}\text { 18. SECURITY CLASSIFICATION } \\
\text { OF THIS PAGE } \\
\text { Unclassified }\end{array}$ \\
\hline
\end{tabular}

19. SECURITY CLASSIFICATION
OF ABSTRACT
Unclassified

Unclassified 